\title{
Practice Mode of Police Education Based on Professional Social Cognition
}

\author{
Jinqi Li, Ping He \\ Liaoning Police College \\ Dalian, 116029, Liaoning China \\ lnpolice@126.com
}

\begin{abstract}
According to the purpose of adapting the characteristics of police education to the police team construction and development, this paper puts forward the concept of professional social cognition (PSC) in police education from the achievable characteristics, demand characteristics of police education and fitness of education system and probes further into fitness, quantity between police education and police team construction, based on the characteristics of studying police education in China and combined with the development status of police education. This study shows that the characteristics of police education are embodied in practice attributes of policing management, application attribute of police science. Therefore, we draw a conclusion that running characteristics of police education is cooperative education system based on the PSC and the policing knowledge.
\end{abstract}

Keywords-Police education system, PSC, professional social cognition, police professional promotion, reform of teaching and training

\section{INTRODUCTION}

Police education plays an increasingly important role of police team construction and development in China [1]. The role of education mode in police education development is vital, but it is also complex and dynamic. Police education exhibit numerous different capabilities and scope, and can affect processes of development both directly and indirectly through regular professional cognition training, specialized knowledge learning and experience exchange. Furthermore, police education operate within different policing work demand in which they can play numerous roles and face various challenges. And while there are many challenges in providing adequate education in pursuit of certain goals, there are also promising improvements in police education that increases the impact, quality and effectiveness of police education's role in development and police work change.

Besides, problems existing in the operation modes advance specific research contents for the police education system. Under different operation modes, police education system as well as management incorporated into one body, the professional capability will assume different knowledge demand. In many literatures [2-4], the researchers basically categorize professional capability of police into management science, social science and information technology demand. In the field of research on policing work, police education have long played a key role, while in the field of social science and information technology research has been undertaken more recently. More and more attention is now being paid to this field. Despite the fact that modern advanced information science are widely used in various fields in the society, which promotes the development of economic development and the society, the police education research field still lags behind. For example, police theory research workers take advantage of a wide range of police science methods in seeking a police education model. Despite these advances, many problems have not yet received satisfactory solutions. Indeed, some of them have not received solutions at all. That is to say, the crucial problem as to how police education play their proper role in the police science research field hinges on correct recognition of a police education mechanism.

In recent years the research of police education in the educational goals, specifications of police training has been given greater prominence in many literatures [5-7]. The purpose of this study was to establish a kind of police education system which can adapt to the police professional characteristics and the requirements of the development, and provided is a support of decision-making and management through the system design and the education evaluation for the decision makers and managers. This paper, based on the research of Refs [1-7], will conduct research on issues relating to the innovation of the policing education from the perspective of police team development strategy.

The paper is structured as follows: We present the operation modes of police education system in sections 2 . Sections 3 contain the author's main ideas on how to research on professional social cognition and police education, police professional promotion. Finally, section 4 contains the main conclusions and future work.

\section{STRUCTURAL DRAWING OF POLICE EDUCATION SYSTEM}

The practical experience and theoretical research on police education have shown that the role of Police Education is mainly reflected in the effective improvement of the three aspects: policing modes, operation object and knowledge systems in addition to police education systems. Advancing the social means and operation modes parallel with the advances in knowledge systems will become the development trend over the next two decades. In particular, in planning and design of police education development strategy of a country or various regions, the issues of operation modes and objects are taken out as a special topic for research, thus demonstrating their 
significance to the research. However, these researches all ignored a crucial problem, i.e., the relationship between social policing needs and operation model of Police Education.

Police education is generally understood to talent cultivation, including the knowledge of police science, and the skills of policing practice, which are conducive to individual profession capacity. If we critically analyze the different concepts of police education, we can list the various roles police education plays in the society. Police Education provides opportunities for lifelong learning of police, allowing people to upgrade their knowledge and skills from time to time based on the needs of the police work.

As the police education and training is a system engineering, therefore, a police education and training operation system in line with social and economic development must be established. Under different knowledge innovation, talent cultivation levels, corresponding to a police knowledge system, social perception process and police cognition model will be formed. Therefore, basic structure of police education operation system can be established with regard to the police psychological, policing skills, policing experience and police knowledge, as is shown in Fig. 1.

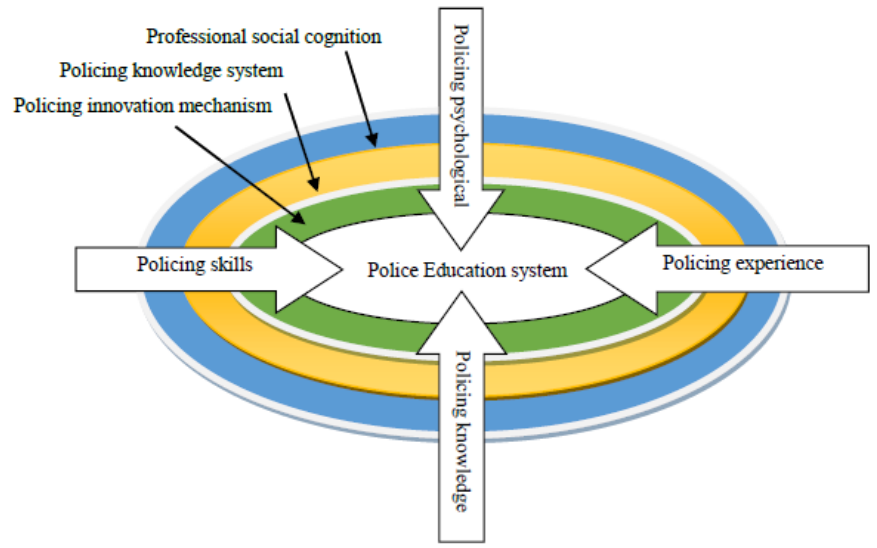

Fig. 1. Structural drawing of the police education system

Police education is also seen as cultivating and inculcating professional capability and moral values in police jobs. As such, the police education play an integral role in the police team construction and development. Knowledge-based approaches, including fitness education theory and critical pedagogies borrow heavily from the profession capacity of police. How do the benefits of fitness police education permeate profession capacity and impact larger policing model change? What aspects of fitness police education enable by the police education as agents of policing innovation and how can this education best serve as a catalyst for police jobs development? In the traditional mode of police education, police education constitute a form of specialized profession education and training. What used to be referred to as "police man-power planning," police education provides the police knowledge base, policing skills, and training to perform specific tasks and jobs of social management.

\section{Police Education Based on Professional Social COGNITION}

\section{A. Professional social cognition and police education}

The theoretical construct predominantly used when studying policing cognition and education practice is a professional social cognition (PSC). PSC is self-reflexive and is a cybernetic input-throughput-output-feedback model. SPC helps explain the environmental influences people's policeman have had over the years shaping them into who they are today. The attitudes and behavior about the police cognition come from their environment of family, school, friends and society. As polices learn over the years through social interaction, they begin to understand and form their values, knowledge, and attitudes about policing management. Family, friends, school and media all shape police's knowledge and attitudes over time [4]. This study combines PSC and family cognition influences theory (FCIT) in a way that considers environmental influences that shape where a policeman is in regards to their knowledge, attitudes, and personal characteristics.

The focus of this study is the policing knowledge, attitudes, and behaviors of police along with the two key environmental influences of family and social that help shape policeman capacity. The environmental influences of family and friend focused on for this study because of the great influence they have on police's social knowledge, attitudes, and behaviors. Family tend to have a greater influence while peer influence increases as the police becomes older. The addition of these environmental influences to our understanding of police's professional knowledge, attitudes, and behavior is a major contribution of this study (see Fig. 2).

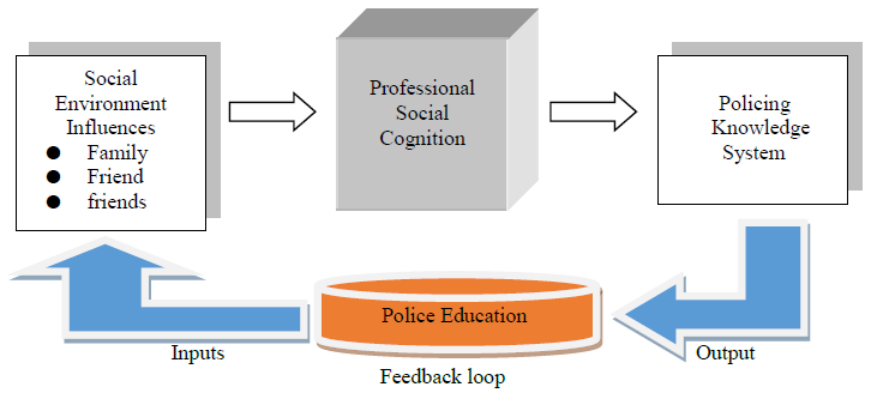

Fig. 2. Professional social cognition of police education

The present research used policing cognition model based on PSC, to understand the policing practices of police education. We also examined the data through the survey of PSC. There are four stages in the policing cognition model, as developed by Literature [1], explain how police's make decisions and to improve policing ability. The four stages are inputs, education process, outputs, and feedback loop. For this study, we only examined the inputs and education process sections of the model and added the environmental influences of family and social. The outputs and feedback sections of the model were beyond the scope of this study. To measure outputs and feedback requires longitudinal data, which we did not gather for this study. 
Policing cognition research at police plays an indispensable role in police education, albeit a very complex and perhaps an indirect one, not only does it create and increase knowledge and ways of understanding, but also informs the idea of policing. As such, the cognition education of polices is important for the independent development of a police itself, as well as for the development of the police force. That is to say, policing cognition research of policing management is assumed to be a vital part of the role of police. However, there is a growing need to question the paradigms of knowledge and innovation that inform the research carried out by police education and its application in wider social practice; and the way that society and police team development needs shape the research agenda itself.

Despite its widespread use in literature, the traditional way of conceptualizing police capacity solely as either policing skills or police knowledge is deemed inadequate to encompass the visions of police education in the 21 st century. Police cognition is a process of turning police knowledge, attitudes and behavior into meaning, understanding, and new ideas. This process would require polices to understand the rationale behind using knowledge as well as actually knowing the exact procedures of conducting the information search. Polices need to 'know-how', but more importantly, they must first 'knowwhy'. Hence, the police education process is improve the social cognition of the police through learning. In this regard, we argue that police cognition should be framed in a way to empower polices to develop in them the capacity for lifelong learning, and to assume greater autonomy and social responsibilities over their learning. The notion of police cognition should be broadened to embrace a wider spectrum of learning outcomes manifested in different dimensions of learning in the information age.

\section{B. Police professional promotion}

Police professional promotion is concerned with improving police cognition by seeking to influence lifestyles, education and learning model and, above all, environments (which are not limited to the work environment but encompass as well the cultural and socioeconomic circumstances that substantially determine police cognition status). Police professional promotion has its roots in many different disciplines. Over time it incorporated several previously separate components, one of which was police professional education. Some authorities hold the view that police professional promotion comprises three overlapping components: includes educational efforts to influence lifestyles and way to work that guard against risk as well as efforts to encourage participation in social practice [6]. Policing professional promotion education, as shown in Fig. 3.

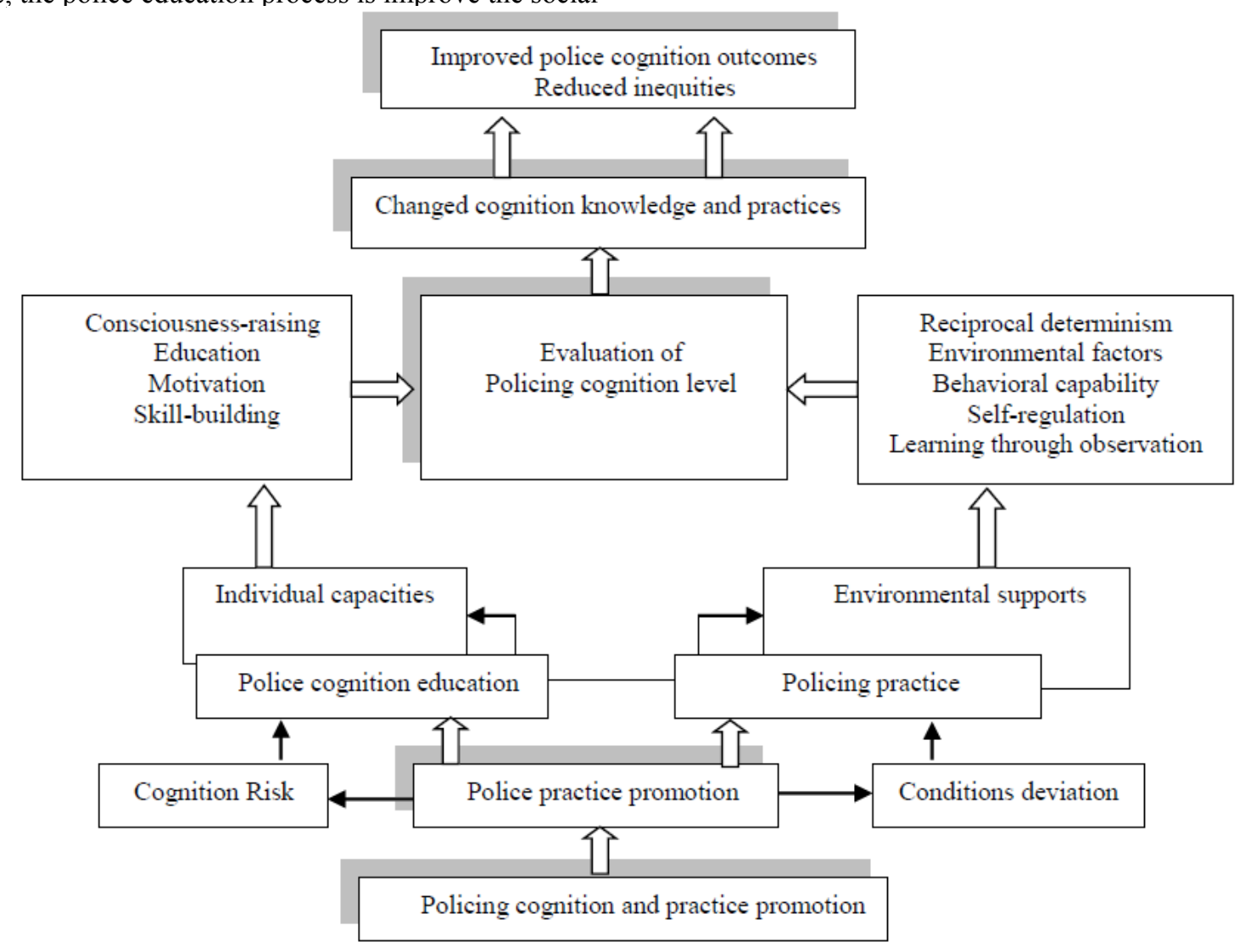

Fig. 3. Structural drawing of policing cognition and practice promotion

Focuses on building individuals' capacities through educational, motivational, skill-building and consciousnessraising techniques. Police education is provides the environmental supports that will encourage and enhance behavior change. By influencing both these intrinsic and extrinsic factors, meaningful and sustained change in the police 
cognition of individuals and communities can be realized [7]. This relationship is illustrated in greater detail in Fig. 3.

Policing cognition research at police plays an indispensable role in police education, albeit a very complex and perhaps an indirect one, not only does it create and increase knowledge and ways of understanding, but also informs the idea of policing. As such, the cognition education of polices is important for the independent development of a police itself, as well as for the development of the police force. That is to say, policing cognition research of policing management is assumed to be a vital part of the role of police. However, there is a growing need to question the paradigms of knowledge and innovation that inform the research carried out by police education and its application in wider social practice; and the way that society and police team development needs shape the research agenda itself.

\section{CONCLUSIONS}

According to the mode of police education in China, we can carry out research and planning on the ratio of input relationship in terms of improving the policing work of police department. Based on the practice academy of Police Education and according to the current police education development scale, we can determine in which fields police education modes can be adopted and in which fields we need to further carry out research, development and application. In addition, we can determine the possibilities of practice academic research on Police Education. However, it is recommended to take into account the relationship of police knowledge and policing practice in the research field and decide on the feasibility of police education research of the policing work from the situation as a whole and in view of the cost benefit, short-term demand and long-term interests. In the light of the hierarchical structure of the academy problems of policing practice, the basic framework of research and planning is based on the knowledge system of policing work.

\section{REFERENCES}

[1] Jinqi Li, Ping He. A Research on Police Higher Education's Contribution to Social Management in China, Proceedings of 2013 World Congress on Education, 2013, pp.194-199.J. Clerk Maxwell, A Treatise on Electricity and Magnetism, 3rd ed., vol. 2. Oxford: Clarendon, 1892, pp.68-73.

[2] Band Bandura, A. Human Agency in social cognitive theory. American Psychologist, 1989, 44, pp.75-1184.

[3] Anderson, E. S., Winnett, R. A., \& Wojcik, J. R. Self-regulation, selfefficacy, outcome expectations, and social support: Social cognitive theory and nutrition behavior. Annals of Behavioral Medicine, 2007, 34, pp.304-312.

[4] Bandura, A. Social cognitive theory: An agentic perspective. Annual Review of Psychology, 2001, 52, pp.1-26.

[5] Taymoori, P, Rhodes RE, Berry. Application of a social cognitive model in explaining physical activity in Lranian female adolescents. Health Education Res, 2010, 25, pp.257-267.

[6] Mehta P, Sharma M, Bemard A. Social cognition theory as a predictor of dietary behavior and leisure time physical activity behavior in middleaged Asian Indian women residing in United States. Int Q Community Health Educ, 2010, 30, pp.257-269.

[7] Sallis JF, Grossman RM, Pinski RB, Patterson TL, Nader PR. The development of scales to measure social support for diet and exercise behaviors. Prev Med, 1987, 16, pp.825-836.

[8] LZ Karvalics, From Scientific Literacy to Lifelong Research: A Social Innovation Approach, Springer International Publishing, 2013.

[9] D Saribas, Investigating the Relationship between Pre-Service Teachers' Scientific Literacy, Environmental Literacy and Life-Long Learning Tendency, Science Education International, 2015, 26, pp.80-100. 